\title{
Development and Analysis of a Dual Input Buck-Boost DC-DC Converter Topology for Hybrid Energy Applications
}

\author{
Sivaprasad Athikkal \\ Department of Electrical and Electronics Engineering, \\ SRM Institute of Science and Technology \\ Kattankulathur, Tamil Nadu, India \\ sivanuday@gmail.com
}

Abstract: In this Paper, a Dual Input buck - boost DC-DC (DIDC) converter is introduced for the integration of two input energy sources. The converter is capable of integrating energy sources which have different V-I characteristics. The output equation of the DIDC converter is derived from different working states using voltage - second principle. The voltage and current stress analysis of the converter are also carried out. The detailed study of the converter is conducted in the MATLAB/Simulink platform and the results are validated through laboratory experiments.

Keywords: Hybrid energy system; dual input DC-DC converter; voltage and current stress; DIDC converter.

\section{Introduction}

A suitable power electronic converter is an essential requirement to fulfill the realization of the concept of Hybrid Energy System (HES). Usually single input DC-DC converters that are connected in parallel configuration are widely opted to integrate multiple energy sources. In addition, a DC-AC inverter circuit is also required for powering AC loads from the HES system. Typical DC-DC boost, buck and buck-boost converter are used as the major power electronic interface in most of the HES related literature papers. The SEPIC and Ćuk converter are also used in some of the applications for the integration of input energy sources [1]-[4]. Complex control strategies, high cost, bulk size and lower efficiency are the outcomes of the traditional integration method using parallel connected single input DC-DC converters. So the concept of Multi-Input DC-DC (MIDC) converters is introduced to outshine the demerits of usual methods. The MIDC converters can be basically classified into isolated type MIDC converter and nonisolated type MIDC converter. Single/multiple winding transformers are available in the isolated type MIDC converters to provide electrical isolation between the input and load side.

However, the presence of transformer and the associated peripheral circuit requirements makes isolated type MIDC converters complex and bulky structure, high manufacturing cost, lower efficiency and more dependent on circuit parameters. Hence the use of non-isolated MIDC converters is preferred in the applications where efficiency and cost of the system are significant concerns.

A structure of multi input buck-boost DC-DC converter is proposed in [5]. The proposed topology is capable to integrate multiple energy sources with distinct voltage-current characteristics. The proposed topology has lower component count with comparatively good efficiency profile. The converter is only capable to perform the buck-boost mode of operation. A generalized and systematic approach to extract MIDC converters is introduced in [6]-[7]. Here the proposed topologies can ensure the power flow from all the input energy sources to the load. The concept of integrating PVSC and PCSC with the conventional DC-DC converters like boost, buck, buck-boost, SEPIC, Ćuk, ZETA etc., to develop different MIDC converters is explained in a detailed manner.

A dual input DC-DC buck type converter for hybrid power system application is presented in [8]. The mathematical model of the converter has been derived for the purpose of investigating the dynamic and steady state behavior of the converter. The concept of the MIDC converter with cascading structure has been explained in [9]. The proposed converter is boost type converter with comparatively high voltage gain. A fuzzy logic control has been developed for the purpose

Received: July $21^{\text {st }}, 2020$. Accepted: November $2^{\text {nd }}, 2020$ DOI: $10.15676 /$ ijeei.2020.12.4.11 
of voltage regulation and maximum power point tracking. A dual input DC-DC converter devoted to low or high voltage input sources are introduced in [10]. Similarly, various MIDC converters for the applications like DC microgrid, renewable energy integration etc., are reported in $[11]-[26]$.

A Dual Input buck - boost DC-DC (DIDC) converter is introduced in this paper for the integration of two input energy sources. The converter is capable of integrating energy sources which have different V-I characteristics. Detailed analysis and performance evaluation of the converter are included in this paper.

\section{Dual Input Buck-boost DC-DC Converter}

As reported in the literature, dual input DC-DC converters are widely used for integrating different input energy sources. These sources have different voltage-current (V-I) characteristics. So, it is important to select a suitable DC-DC converter that can accommodate input energy sources which have different characteristics, with lower part count and compact structure. A Dual Input buck-boost DC-DC (DIDC) converter is presented for the integration of two input energy sources with distinct V-I characteristics and the basic circuit diagram of the converter is shown in Figure 1. In the DIDC converter, two input energy sources i.e., source -1 (i.e., $\mathrm{V}_{1}$ ), and source - 2 (i.e., $V_{2}$ ) share a single inductor ' $L$ ' through two power switches $S_{1}$ and $S_{2}$ that are connected to the respective sources. Two diodes $D_{a}$ and $D_{b}$ are connected in series with the switches $S_{1}$ and $S_{2}$ respectively to avoid the flow of circulating current between the sources. The output side of the converter consists of a diode ' $\mathrm{D}$ ' and a capacitor ' $\mathrm{C}$ ' which are connected in parallel with the load.

\section{A. Working States of DIDC Converter}

Based on the operation of the power switches in the DIDC converter, the converter has three working states in a single switching cycle. The inductor voltage and inductor current variations due to the change of working states over a single switching cycle have been illustrated in the analytical waveforms shown in Figure 2.

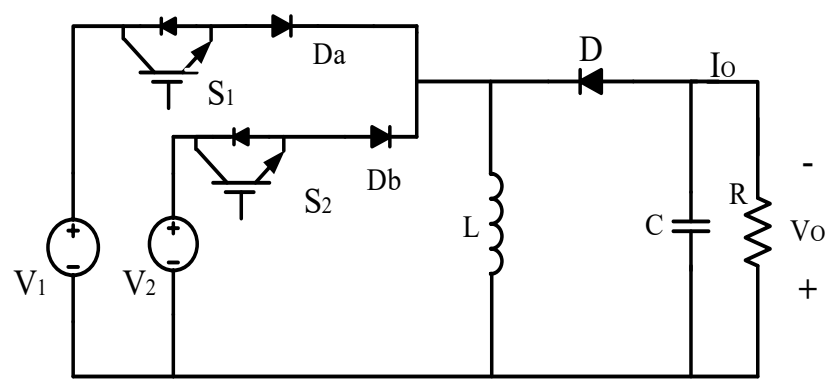

Figure 1. Circuit diagram of the DIDC converter.

State 1:

In this state, the switch $S_{1}$ is conducting, while the switch $S_{2}$ and diode D are OFF. Here, the inductor is charged by source -1 as shown in Figure 3. By applying KVL to the loop containing source $\mathrm{V}_{1}$, switch $\mathrm{S}_{1}$ and the inductor $\mathrm{L}$, the voltage across the inductor $\mathrm{L}$ is

$$
V_{1}=L \frac{d i_{L}}{d t}
$$

By applying KCL at the load side,

$$
C \frac{d V_{C}}{d t}+\frac{V_{C}}{R C}=0
$$

\section{State 2:}

In this state, the switch $\mathrm{S}_{2}$ is turned $\mathrm{ON}$, while the switch $\mathrm{S}_{1}$ and diode $\mathrm{D}$ are non-conducting. Hence, the inductor is charged by source $V_{2}$ as shown in Figure 4. By applying KVL to the loop containing source $V_{2}$, switch $S_{2}$ and the inductor $L$, the voltage across the inductor $L$ is

$$
V_{2}=L \frac{d i_{L}}{d t}
$$


By applying KCL at the load side

$$
C \frac{d V_{C}}{d t}+\frac{V_{C}}{R C}=0
$$

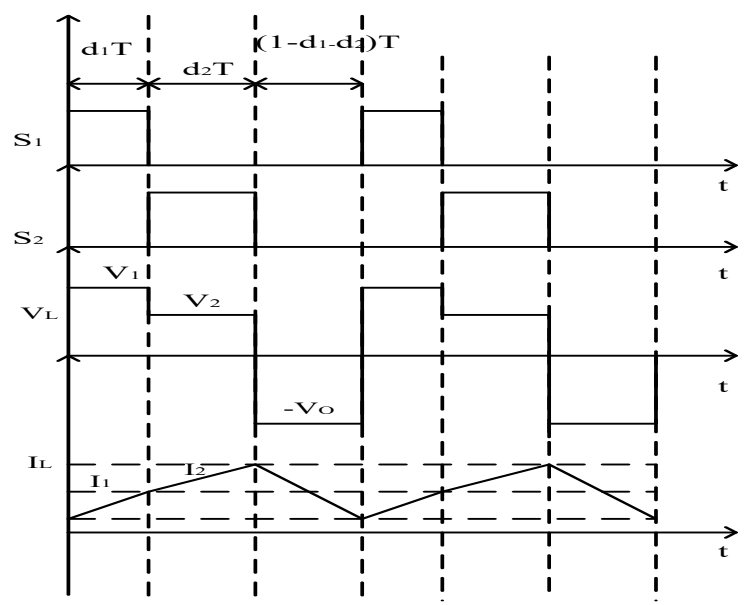

Figure 2. Analytical waveform of switching signal, inductor voltage and current, for DIDC converter.

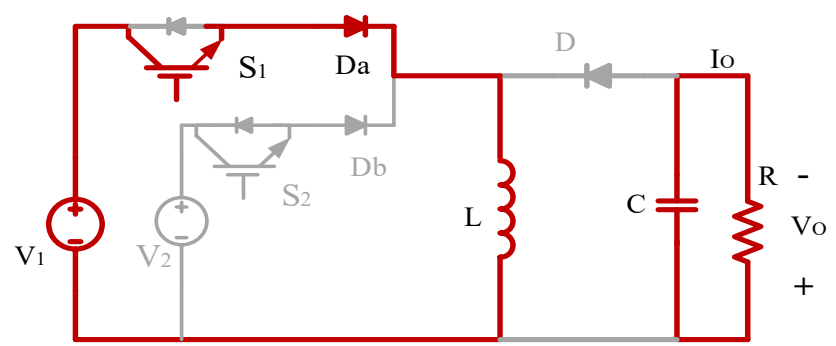

Figure 3. Converter operation with switch $\mathrm{S}_{1}$ closed and $\mathrm{S}_{2}$ opened.

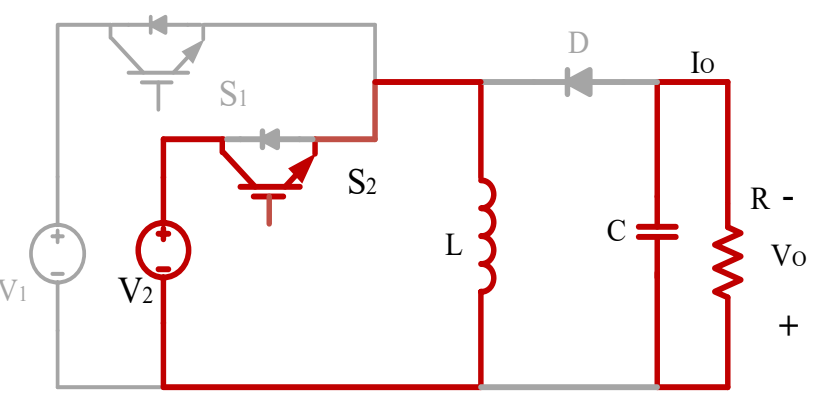

State 3:

Figure 4. Converter operation with switch $\mathrm{S}_{2}$ closed and $\mathrm{S}_{1}$ opened.

In this mode, both switches (i.e., $\mathrm{S}_{1}$ and $\mathrm{S}_{2}$ ) are OFF. Thus the inductor is dissipated its energy to the load and the capacitor as shown in Figure 5. The diode D acts as a freewheeling diode, when the inductor delivers energy to the load. By applying KVL to the loop containing inductor $\mathrm{L}$, diode $\mathrm{D}$, capacitor $\mathrm{C}$, and the load resistance $\mathrm{R}$, the voltage across the inductor $\mathrm{L}$ can be calculated as:

$$
-V_{C}=L \frac{d i_{L}}{d t}
$$

By applying KCL at the load side,

$$
C \frac{d V_{C}}{d t}+\frac{V_{C}}{R C}=I_{L}
$$




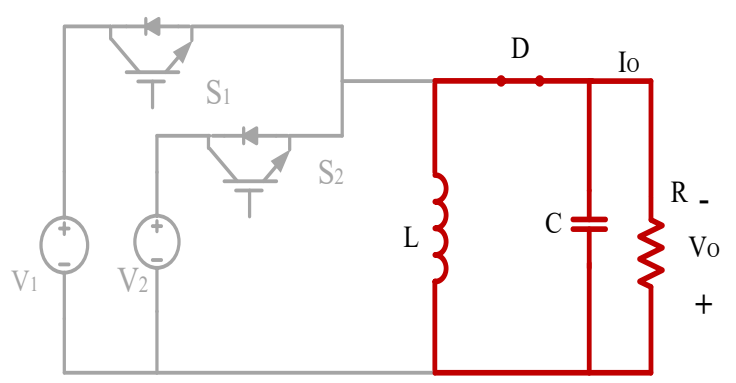

Figure 5. Converter operation with switches $S_{1}$ and $S_{2}$ opened.

The three modes of operation of the DIDC converter are explained so far. For computing the relation between the output voltage of the converter with respect to the input voltages, the VoltSecond (V-S) balance principle of the inductor is used. As per the voltage second balance principle,

$$
V_{1} d_{1} T+V_{2} d_{2} T-V_{0}\left(1-d_{1}-d_{2}\right) T=0
$$

Dividing the above equation by the switching period $T$ and further simplification,

$$
V_{1} d_{1}+V_{2} d_{2}-V_{0}\left(1-d_{1}-d_{2}\right)=0
$$

From the above equation, the output voltage of the DIDC converter is given by:

$$
V_{0}=\frac{V_{1} d_{1}+V_{2} d_{2}}{\left(1-d_{1}-d_{2}\right)}
$$

Since the converter already has a negatively referenced output voltage like the conventional buck-boost converter as shown in Figure 1, (9) does not contain any negative sign. The design equations of the DC-DC buck boost converter are shown below. Like the conventional buckboost converter, the value of the inductor can be calculated based on the ripple content $\Delta i_{L}$ in the inductor current. Referring to the analytical waveform of the converter shown in Figure 2, the slopes of the inductor current for the period $d_{1} T$ and $d_{2} T$ are

$$
\begin{aligned}
& \frac{d i_{L}}{d t}=\frac{\Delta i_{L}}{\Delta t}=\frac{\Delta i_{L}}{d_{1} T}=\frac{V_{1}}{L} \\
& \frac{d i_{L}}{d t}=\frac{\Delta i_{L}}{\Delta t}=\frac{\Delta i_{L}}{d_{2} T}=\frac{V_{2}}{L}
\end{aligned}
$$

Similarly, slope of the inductor current for the period $\left(1-d_{1}-d_{2}\right) T$ is

$$
\frac{d i_{L}}{d t}=\frac{\Delta i_{L}}{\Delta t}=\frac{\Delta i_{L}}{\left(1-d_{1}-d_{2}\right) T}=\frac{V_{0}}{L}
$$

Here since the inductor current slopes are different for different ON periods, it is better to estimate the value of ' $L$ ' using the inductor current slope shown in (12) as given below:

$$
L=\frac{V_{0}\left(1-d_{1}-d_{2}\right)}{\Delta I_{L} f}
$$

where, $\Delta i_{L}$ is assumed as $10 \%$ of $I_{\text {in }}+I_{0}$ in this study, and $f=\frac{1}{T}$ is the switching frequency in $\mathrm{Hz}$.

The value of the capacitor is calculated by the principle of the amp-second rule. So, it can be derived as follows:

$$
\Delta Q=C \Delta V_{0}=I_{0} d T
$$

But here, $d T=\left(d_{1}+d_{2}\right) T$ and $I_{0}=\frac{V_{0}}{R}$, so, (14) can be modified as

$$
C=\frac{V_{o}\left(d_{1}+d_{2}\right)}{R \Delta V_{o} f}
$$

Where, $\Delta V_{o}$ is the ripple voltage and it is assumed as $2 \%$ of $V_{0}$ in this study. Based on the three working states of the DIDC converter, the output voltage of the converter and the values of $\mathrm{L}$ and $\mathrm{C}$ are obtained.

\section{B. Voltage and Current Stress Analysis}

Appropriate selection of the power switches and diodes present in the converter is very crucial for the efficient and cost effective operation of the DIDC converter. Hence, the voltage 
and current stress analysis of the switching devices of the converter has to be conducted to make sure their excellent and optimized selection. The maximum value of peak voltage across the switches $\mathrm{S}_{1}, \mathrm{~S}_{2}$ in DIDC converter is $\mathrm{V}_{1}, \mathrm{~V}_{2}$ respectively. Hence the voltage stress of the power switches can be extracted as follows:

\section{State 1 operation:}

According to state 1 operation, shown in Figure 3, the voltage stress across the switch $S_{1}$ is zero. By applying the KVL to the loop of $V_{1}, V_{2}, S_{1}$ and $S_{2}$, the voltage stress across the switch $S_{2}$ is derived as given below:

$$
V_{S 2 \_S T R E S S}=V_{2}-V_{1}
$$

State 2 operation:

According to state 2 operation, shown in Figure 4, the voltage stress across the switch $\mathrm{S}_{2}$ is zero. By applying the KVL to the loop of $V_{1}, V_{2}, S_{1}$ and $S_{2}$, the voltage stress across the switch $S_{1}$ is derived as:

$$
V_{S 1 \_S T R E S S}=V_{1}-V_{2}
$$

State 3 operation:

According to state 3 operation, shown in Figure 5, the voltages stress across the switches $\mathrm{S}_{1}$ and $\mathrm{S}_{2}$ are extracted as follows:

$$
\begin{aligned}
& V_{S 1 \_S T R E S S}=V_{1} \\
& V_{S 2_{2} S T R E S S}=V_{2}
\end{aligned}
$$

The current stress analysis of the switches can be performed out based on the different operating conditions of the converter which are already described. The current stress values for the power switches are derived as given below:

$$
\begin{aligned}
& \text { Current through switch } \left.\mathrm{S}_{1} \text { (i.e., } I_{S 1}\right)=\left\{\begin{array}{c}
I_{L} \text { for } d_{1} T \\
0 \text { for }\left(1-d_{1}\right) T
\end{array}\right. \\
& \text { Current through switch } \left.\mathrm{S}_{2} \text { (i.e., } I_{S 2}\right)=\left\{\begin{array}{c}
I_{L} \text { for } d_{2} T \\
0 \text { for }\left(1-d_{2}\right) T
\end{array}\right.
\end{aligned}
$$

The diode current $\mathrm{I}_{\mathrm{D}}$ for DIDC converter is given as

$$
I_{D}=\left\{\begin{array}{c}
I_{L} \text { for }\left(1-d_{1}-d_{2}\right) T \\
0 \text { for }\left(d_{1}+d_{2}\right) T
\end{array}\right.
$$

Hence, the current stress of the switches is derived as the sum of current through the switch during the particular time interval and associated inductor current ripple. The inductor current ripple for each time interval can be derived from (10) - (12). So, the current stress of the semiconductor devices available in the converter shall be expressed as:

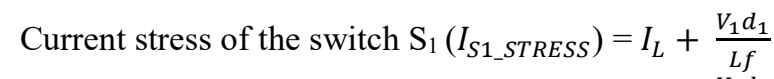

Current stress of the switch $\mathrm{S}_{2}\left(I_{S 2_{-} S T R E S S}\right)=I_{L}+\frac{V_{2} d_{2}}{L f}$

Current stress of the diode D

$$
I_{D_{S T R E S S}}=I_{L}+\frac{V_{0}\left(1-\left(d_{1}+d_{2}\right)\right)}{L f}
$$

From the analysis, it is noticed that the input source voltage magnitude is the major deciding factor for the currents stress values through the power switches, and the magnitude of the output voltage is the major deciding factor for the diode current stress. Hence the detailed investigation of the voltage and current stresses values of the power switches and diodes are helpful for the proper selection of the switching devices.

\section{Simulation Analysis}


The simulation studies of the presented DIDC converter are performed in MATLAB/Simulink platform by considering the ideal behaviour of various components present in the converter. The parameters of the DIDC converter taken into account for the simulation/experimental purpose are given in Table 1. Two different input voltage ranges such as source 1 voltage of $90 \mathrm{~V}$ and source 2 voltage of $70 \mathrm{~V}$ are considered to check the performance of the DIDC converter. The output voltage is considered as $110 \mathrm{~V}$ for the boost operation and $48 \mathrm{~V}$ for the buck operation of the converter. The switching frequency of the converter is considered as $20 \mathrm{kHz}$. Based on these values, the value of inductor and capacitor of the DIDC converter is computed and given in Table 1.

Table1.Simulation/experimental parameters of the converter

\begin{tabular}{ccccccc}
\hline \hline \multirow{2}{*}{$\begin{array}{c}\text { Source } 1 \\
(\mathrm{~V})\end{array}$} & $\begin{array}{c}\text { Source } 2 \\
(\mathrm{~V})\end{array}$ & $\begin{array}{c}\text { Inductor } \\
(\mathrm{mH})\end{array}$ & $\begin{array}{c}\text { Capacitor } \\
(\mu \mathrm{F})\end{array}$ & $\begin{array}{c}\text { Switching } \\
\text { frequency } \\
(\mathrm{kHz})\end{array}$ & \multicolumn{2}{c}{$\begin{array}{c}\text { Output voltage } \\
(\mathrm{V})\end{array}$} \\
\hline 90 & 70 & 5 & 100 & 20 & Boost & Buck \\
\hline
\end{tabular}

The current stress values of the DIDC converter for the buck operation i.e., duty ratio $\left(d_{1}+\right.$ $\left.d_{2}\right)<0.5$ and boost operation i.e., $\left(d_{1}+d_{2}\right)>0.5$ are calculated based on the analysis reported in the previous section. The current stress values are given in Table 2 . Similarly the voltage stress values of the power switches $S_{1}$ and $S_{2}$ based on (16) - (19) are given in Table 3. From these analyses it is possible to choose proper power switches and diode which can tolerate the calculated current and voltage stress values given in Table 2 and Table 3 respectively. The performance study of the DIDC converter is carried out in simulation environment. The computer simulation of the DIDC converter is developed in MATLAB/Simulink platform using the power system block sets. The steady state waveforms such as inductor voltage, inductor current, output voltage and output current of the DIDC converter are shown in Figure 6(a) for the buck operation of the converter and in Figure 6(b) for the boost operation.

Table 2. Current stress of the switching devices in DIDC converter

\begin{tabular}{|c|c|c|}
\hline \multirow{2}{*}{ Power switches/Diodes } & \multicolumn{2}{|c|}{ Current stress $(\mathrm{A})$} \\
\cline { 2 - 3 } & For $\left(d_{1}+d_{2}\right)<0.5$ & For $\left(d_{1}+d_{2}\right)>0.5$ \\
\hline $\mathrm{S}_{1}$ & 1.15 & 3.43 \\
\hline $\mathrm{S}_{2}$ & 1.31 & 3.18 \\
\hline $\mathrm{D}$ & 1.61 & 3.97 \\
\hline
\end{tabular}

Table 3. Voltage stress of the switching devices in DIDC converter

\begin{tabular}{|c|c|c|}
\hline Power switches & Voltage stress (V) & Condition \\
\hline \multirow{3}{*}{$\mathrm{S}_{1}$} & 0 & $\mathrm{~S}_{1} \mathrm{ON}$ \\
& $20 \mathrm{~V}$ & $\mathrm{~S}_{2} \mathrm{ON}$ \\
& $90 \mathrm{~V}$ & $\mathrm{~S}_{1}, \mathrm{~S}_{2} \mathrm{OFF}$ \\
\hline \multirow{3}{*}{$\mathrm{S}_{2}$} & 0 & $\mathrm{~S}_{2} \mathrm{ON}$ \\
& $-20 \mathrm{~V}$ & $\mathrm{~S}_{1} \mathrm{ON}$ \\
& $70 \mathrm{~V}$ & $\mathrm{~S}_{1}, \mathrm{~S}_{2} \mathrm{OFF}$ \\
\hline
\end{tabular}

From Figure 6(a), it is observed that the inductor charges by a voltage of $90 \mathrm{~V}$ (i.e., $V_{1}$ ) for duty ratio $d_{1}$ and then charges by a voltage of $70 \mathrm{~V}$ (i.e., $V_{2}$ ) for duty ratio $d_{2}$. Then the inductor discharges with a voltage of $-48 \mathrm{~V}$ (i.e., $-V_{0}$ ) for rest of the period. Similarly for the duty ratio $\left(d_{1}+d_{2}\right)>0.5$, the inductor is charged by $90 \mathrm{~V}$ and $70 \mathrm{~V}$ respectively for the duty ratios $d_{1}$ and $d_{2}$. But in the boost operation, the inductor discharges with a voltage of $-110 \mathrm{~V}$ (i.e., $-V_{0}$ ) as shown in Figure 6(b). Deviation in the slope of the inductor current for the variation of the source voltages can be easily observed from the simulation results. From Figure 6(a) and Figure 6(b), it can also be observed that the source currents of the DIDC converter are discontinuous or pulsating in nature.

\section{Experimental Analysis}


For verifying the feasibility and performance of the DIDC converter, an experimental prototype is developed in the laboratory environment. The testing of the experimental prototype is conducted by taking two input sources of different voltage levels. LabVIEW 2013 software has been adopted for developing the required switching pulses, where real-time interfacing with the hardware is realized with NI cRIO-9081 controller using NI 9401 digital input and output module. NI 9225 and NI 9227 modules are used for the voltage and current sensing purpose. The gate pulses developed for all the switches have the same switching frequency of $20 \mathrm{kHz}$. In this work, IRFP 460 MOSFET is opted as the power switches and the diodes are realized by MUR 860 ultra-fast recovery diodes. The hardware waveforms of the voltage across the inductor, current through the inductor, output voltage and output current for the DIDC converter are observed using the Digital Storage Oscilloscope (DSO) and the observed waveforms are shown in Figure 7. From the figure, it is observed that the inductor charges by a voltage of $90 \mathrm{~V}$ and $70 \mathrm{~V}$ for the ON period of the switches $S_{1}$ and $S_{2}$ respectively which is same as the simulation results. Finally, it is discharged by a voltage of $-110 \mathrm{~V}$ in the freewheeling period.
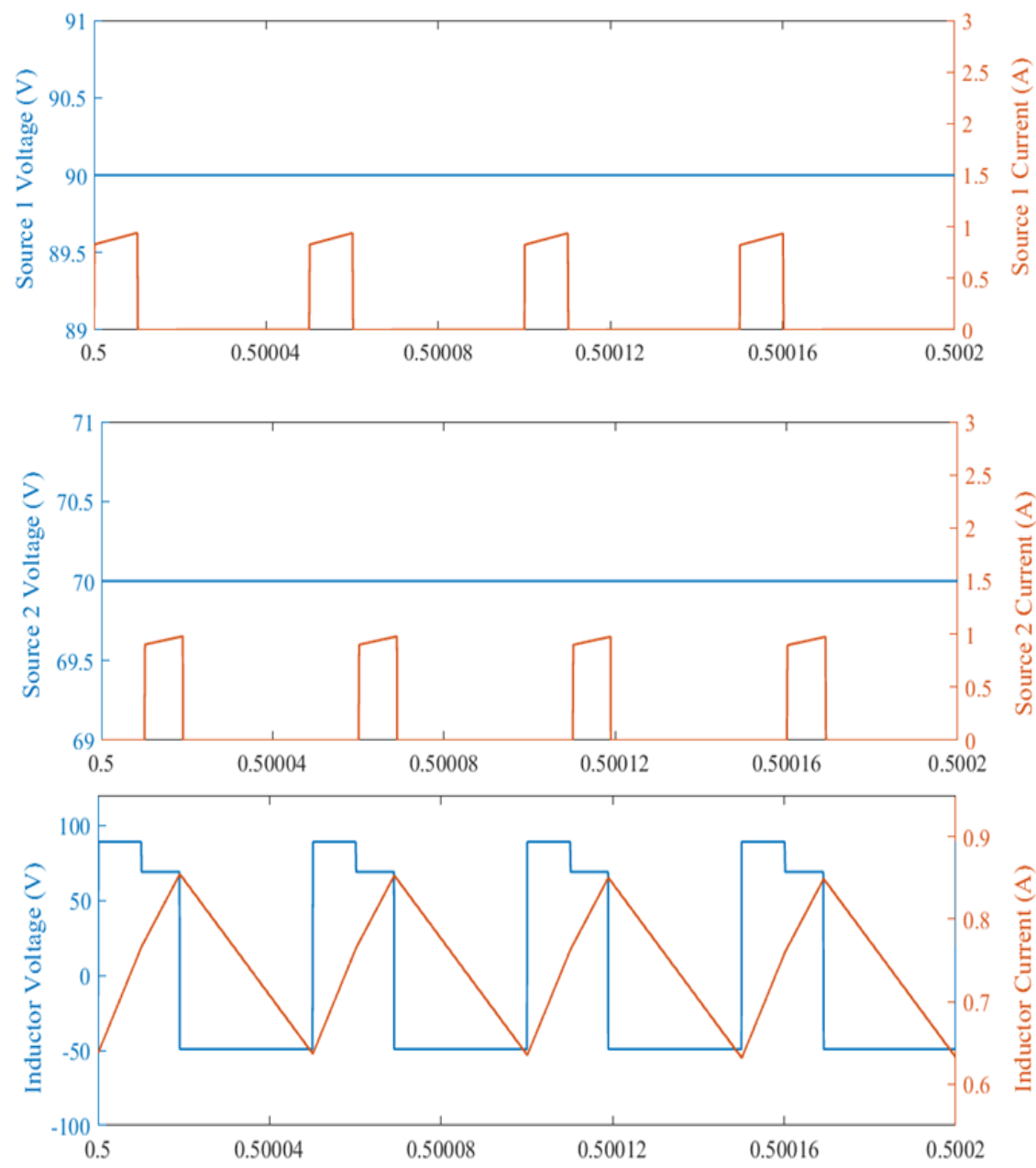


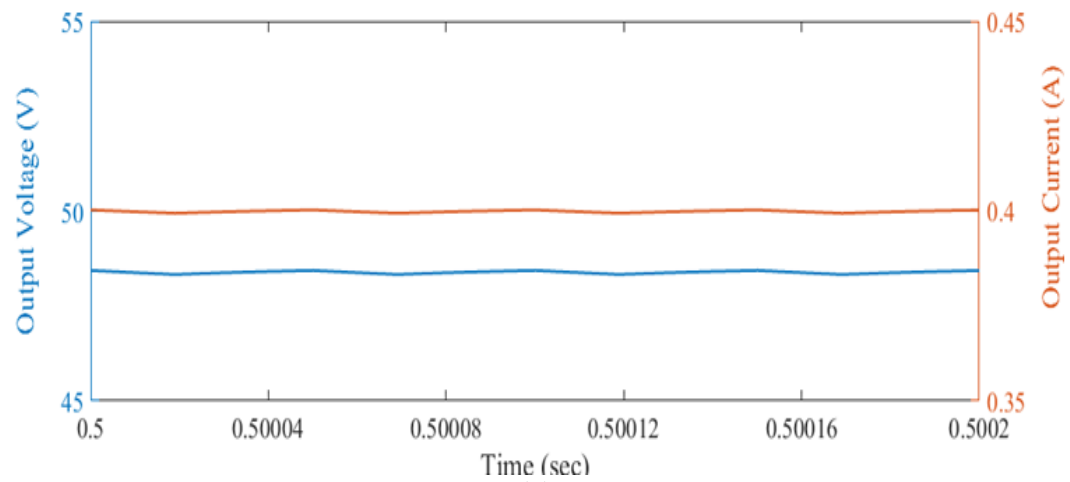

(a).
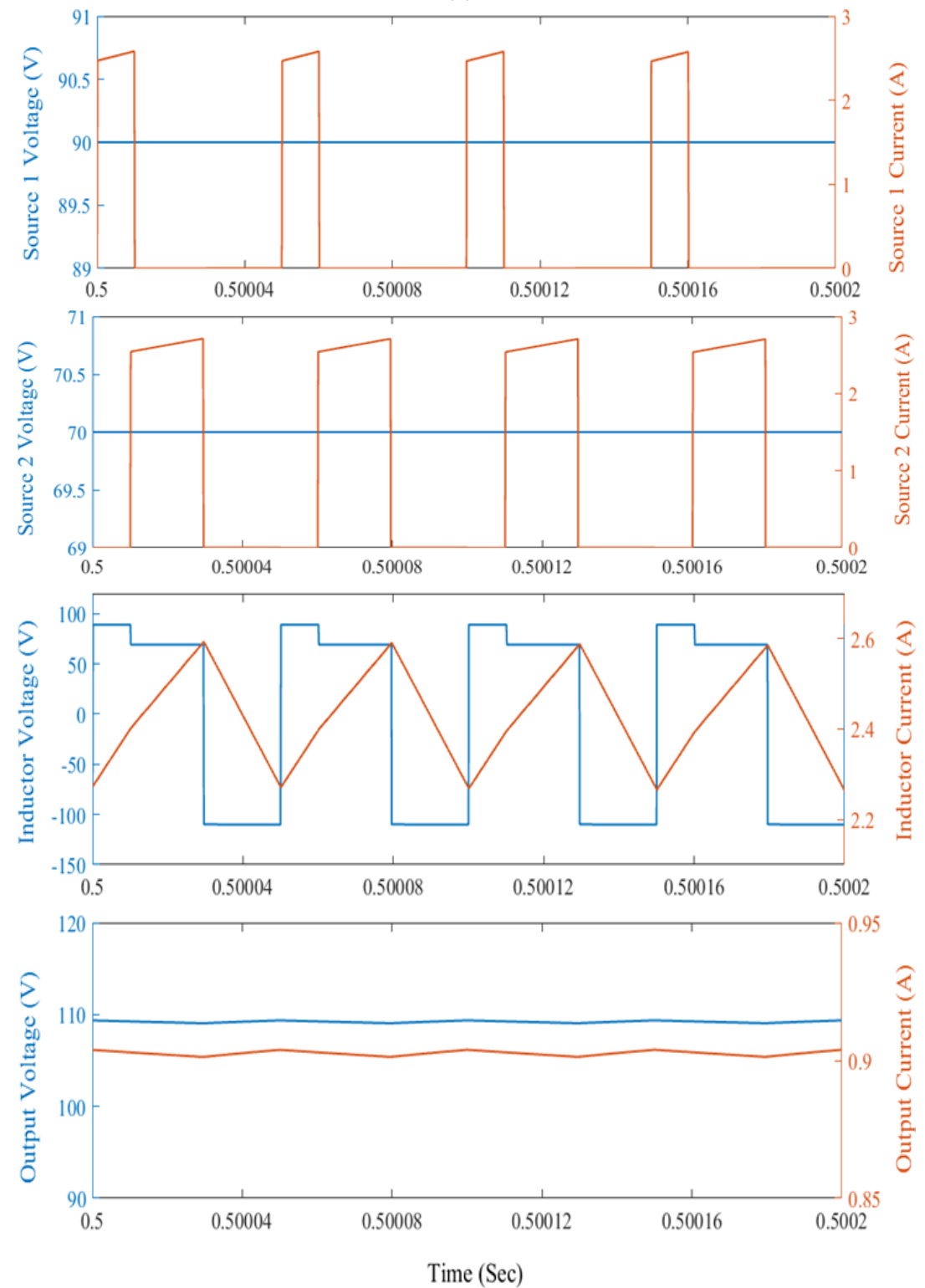

(b).

Figure 6. Simulation waveforms of DIDC converter (a) for $d_{1}+d_{2}<0.5$ (b) for $d_{1}+d_{2}>0.5$. 


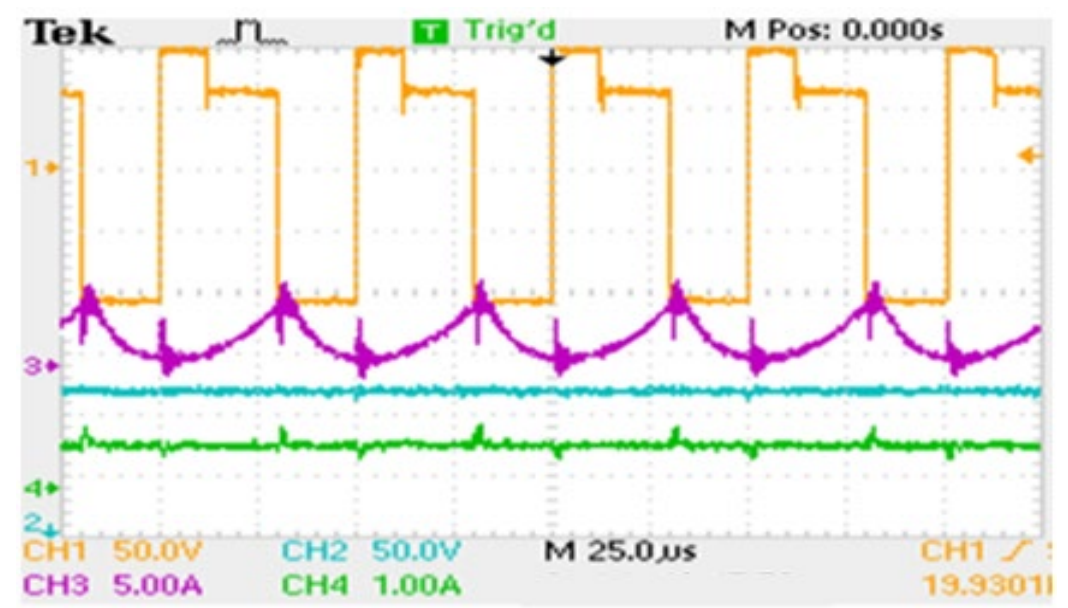

Figure 7. Experimental waveforms of voltage across the inductor, current through the inductor, output voltage and output current of the DIDC converter $(\mathrm{CH} 1=50 \mathrm{~V} / \mathrm{div}, \mathrm{CH} 2=50 \mathrm{~V} / \mathrm{div}$, $\mathrm{CH} 3=5 \mathrm{~A} / \mathrm{div}, \mathrm{CH} 4=1 \mathrm{~A} / \mathrm{div})$.

The output waveforms clearly show that the output voltage of the DIDC converter is $110 \mathrm{~V}$. From Figure 7, it can be noticed that the wave shape and the calculated values of the voltage across the inductor, current through the inductor, output voltage and output current in the experimental platform are exactly matching with the simulation waveforms shown in Figure 6 . This validates the results of the DIDC converter obtained from the simulation with the results of the experiment.

\section{A. Closed loop operation of the DIDC Converter}

Investigation on the dynamic response of the DIDC converter is very much required to validate the converter performance under sudden disturbances. The dynamic behavior of the DIDC converter is tested under the load side variations. To verify the dynamic performance of the DIDC converter, a simple PI controller is designed and implemented in the LabVIEW platform. Ease of hardware interfacing, high processing speed and high flexibility are some of the potential merits of the LabVIEW controller. The PI controller is designed to control the output voltage of the DIDC converter at $110 \mathrm{~V}$. The output voltage and current response due to the variations in the load value are observed and the output waveforms are given in Figure 8. From Figure 8, it is observed that the output voltage is regulated at the preferred value of $110 \mathrm{~V}$ very quickly after a tiny dip under rapid deviation of load current from 0.9A to 1.7A. Similarly, when the load current decreased from 1.7A to $0.9 \mathrm{~A}$, the output voltage is regulated at $110 \mathrm{~V}$ quickly with a tiny spike as given in Figure 8.

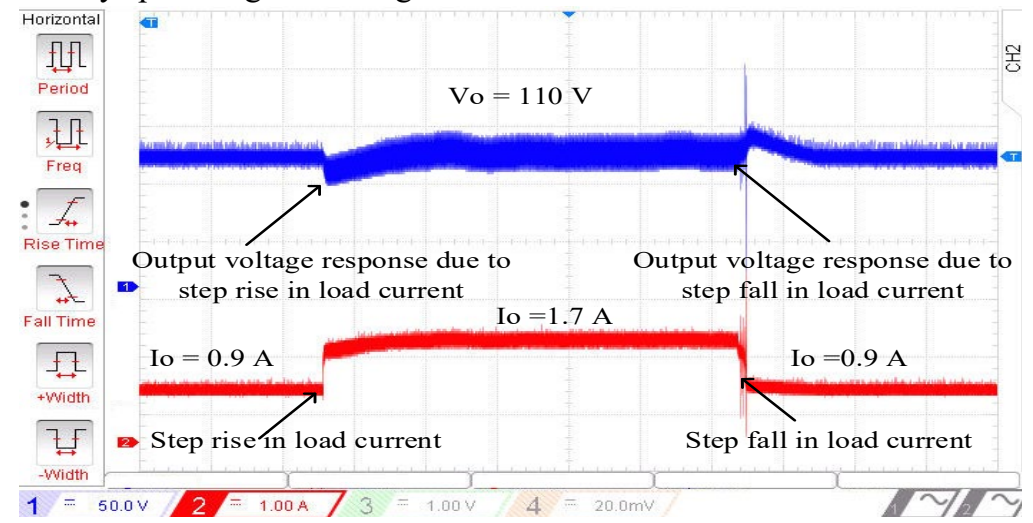

Figure 8. Experimental waveforms of the output voltage and load current of the converter under load variation. 
The efficiency values are plotted with respect to the power variation as given in Figure 9. From the figure, it can be summarized that the efficiency profile of the proposed converter is far better compared to other topologies implemented in the literature. The efficiency of DIDC converter can be improved further by adopting the optimum design of the components present in the converter. However, the DIDC converter produces a negative output voltage across the load and to make the polarity of the output voltage positive using the DIDC converter, additional arrangements are needed. This adds more complexity to the system. This is one drawback of the DIDC converter.

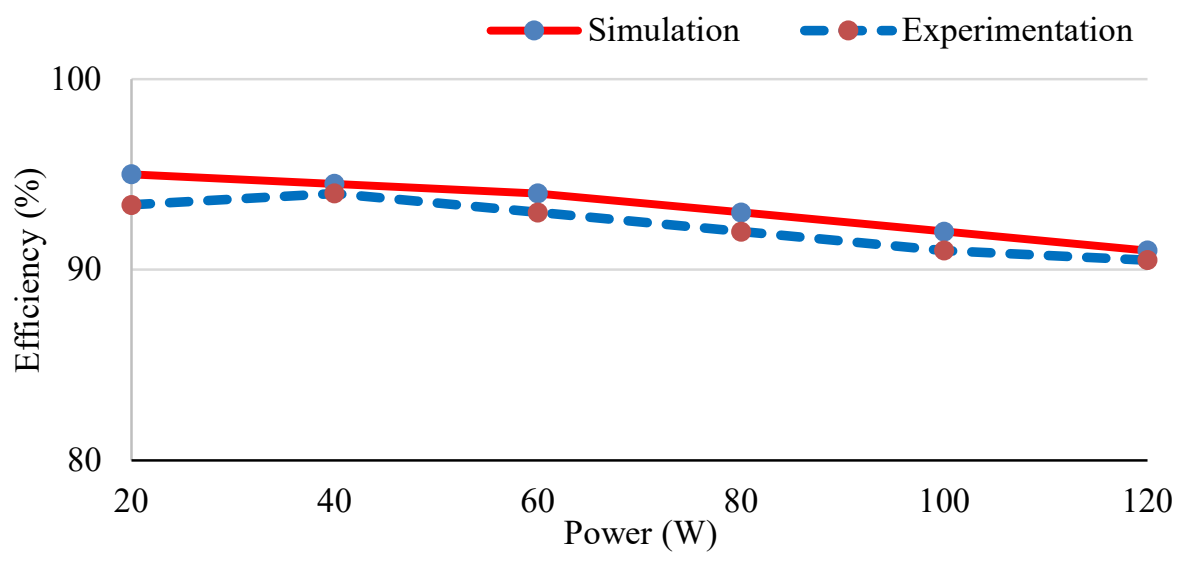

Figure 9. Efficiency versus output power of DIDC converter.

\section{Conclusion}

A dual input buck-boost type DC-DC (DIDC) converter for the integration of hybrid energy sources has been presented in this chapter. Different working modes of the converter are explained in detail. The relation between output voltage and the input voltages is derived. The detailed investigation of the voltage and current stresses values of the power switches and diodes are conducted to make sure the proper selection of the switching components in the converters. The performance of the converter is verified with the help of simulation and experimental results. The simulation and experimental results of the DIDC converter are closely matching. A PI controller is designed to get the satisfactory response of the DIDC converter under steady state and dynamic conditions. Transient analysis of the DIDC converter has been conducted in the experimental platform to verify the feasibility of the PI controller. The efficiency analysis of the DIDC converter is conducted through both experimental and simulation analysis to confirm the superior performance of the converter. From the analysis, it is noticed that the DIDC converter has certain merits such as optimised structure, lower component count due to which the coneverter efficiency is good. These merits definitely boost up the significance of the converter in the specific applications like marine renewable energy integration, microgrid, and hybrid electric vehicle.

\section{References}

[1]. S. Chakraborty, S. M. S. Reza and W. Hasan, "Design and analysis of hybrid solar-wind energy system using CUK \& SEPIC converters for grid connected inverter application," 2015 IEEE 11th International Conference on Power Electronics and Drive Systems, Sydney, NSW, 2015, pp. 278-283.

[2]. T. Maity, S. Kakkar and R. K. Ahuja, "Control of standalone Wind/PV hybrid renewable power generation," 2016 IEEE 7th Power India International Conference (PIICON), Bikaner, 2016, pp. 1-5. 
[3]. H. Zhang, X. Liu, M. Kedia and R. S. Balog, "Photovoltaic hybrid power harvesting system for emergency applications," 2013 IEEE 39th Photovoltaic Specialists Conference (PVSC), Tampa, FL, 2013, pp. 2902-2907.

[4]. Vinayaka K. U. and V. Krishnan, "Applications of fused DC-DC converters using hybrid wind-solar systems," 2016 IEEE 1st International Conference on Power Electronics, Intelligent Control and Energy Systems (ICPEICES), Delhi, 2016, pp. 1-6.

[5]. B. G. Dobbs and P. L. Chapman, "A multiple-input DC-DC converter topology," in IEEE Power Electronics Letters, vol. 1, no. 1, Mar. 2003, pp. 6-9.

[6]. Y. C. Liu and Y. M. Chen, "A Systematic Approach to Synthesizing Multi-Input DC-DC Converters," in IEEE Transactions on Power Electronics, vol. 24, no. 1, Jan. 2009, pp. 116127.

[7]. Y. Li, X. Ruan, D. Yang, F. Liu and C. K. Tse, "Synthesis of Multiple-Input DC/DC Converters," in IEEE Transactions on Power Electronics, vol. 25, no. 9, Sept. 2010, pp. $2372-2385$.

[8]. X. Xiong, C. K. Tse, X. Ruan and M. Huang, "Bifurcation analysis in dual-input buck converter in hybrid power system," 2013 IEEE International Symposium on Circuits and Systems (ISCAS2013), Beijing, 2013, pp. 925-928.

[9]. Bin Le and A. Kwasinski, "Analysis of a flexible and rugged photovoltaic-based power system," INTELEC 2008 - 2008 IEEE 30th International Telecommunications Energy Conference, San Diego, CA, 2008, pp. 1-7.

[10]. Y. M. Chen, Y. C. Liu and S. H. Lin, "Double-Input PWM DC/DC Converter for High/Low-Voltage Sources," in IEEE Transactions on Industrial Electronics, vol. 53, no. 5, Oct. 2006, pp. 1538-1545.

[11]. N. Muntean, M. Gavris and O. Cornea, "Dual input hybrid DC-DC converters," 2011 IEEE EUROCON - International Conference on Computer as a Tool, Lisbon, 2011, pp. 1-4.

[12]. M. Jafari, G. Hunter and Jian Guo Zhu, "A new topology of multi-input multi-output BuckBoost DC-DC Converter for microgrid applications," 2012 IEEE International Conference on Power and Energy (PECon), Kota Kinabalu, 2012, pp. 286-291.

[13]. E. V. Kumar and M. Veerachary, "Steady-state analysis of large step-down ratio two-input DC-DC converter," 2013 International Conference on Control Communication and Computing (ICCC), Thiruvananthapuram, 2013, pp. 352-357.

[14]. M. Veerachary, "Two-Loop Controlled Buck-SEPIC Converter for Input Source Power Management," in IEEE Transactions on Industrial Electronics, vol. 59, no. 11, Nov. 2012, pp. 4075-4087.

[15]. K. P. Yalamanchili and M. Ferdowsi, "Review of multiple input DC-DC converters for electric and hybrid vehicles," 2005 IEEE Vehicle Power and Propulsion Conference, 2005, pp. 160-163.

[16]. R. Zhao and A. Kwasinski, "Multiple-input single ended primary inductor converter (SEPIC) converter for distributed generation applications," 2009 IEEE Energy Conversion Congress and Exposition, San Jose, CA, 2009, pp. 1847-1854.

[17]. Junseok Song and A. Kwasinski, "Analysis of the effects of duty cycle constraints in multiple-input converters for photovoltaic applications," INTELEC 2009 - 31st International Telecommunications Energy Conference, Incheon, 2009, pp. 1-5.

[18]. T. Cheng, D. D. C. Lu and L. Qin, "Non-Isolated Single-Inductor DC/DC Converter with Fully Reconfigurable Structure for Renewable Energy Applications," in IEEE Transactions on Circuits and Systems II: Express Briefs, vol. PP, no. 99, pp. 1-1.

[19]. J. Lam and P. K. Jain, "A novel electrolytic capacitor-less multi-input DC/DC converter with soft-switching capability for hybrid renewable energy system," 2014 16th European Conference on Power Electronics and Applications, Lappeenranta, 2014, pp. 1-10.

[20]. Y. Li, T. Q. Zheng, C. Zhao, R. Du and Quandong Wang, "A novel buck/boost/buck-boost three-input DC/DC converter," IECON 2011 - 37th Annual Conference of the IEEE Industrial Electronics Society, Melbourne, VIC, 2011, pp. 1091-1096. 
[21]. P. Nair and Deepa K., "Two-port DC-DC converter with flyback inverter for rural lighting applications," 2015 International Conference on Technological Advancements in Power and Energy (TAP Energy), Kollam, 2015, pp. 249-253.

[22]. Nayana K., V. Sailaja, Deepa K. and H. V. Manjunath, "A DC-DC multi-output SEPIC converter for suburban power application," 2014 International Conference on Electronics, Communication and Computational Engineering (ICECCE), Hosur, 2014, pp. 55-60.

[23]. Guru Kumar, K. Sundaramoorthy, S. Athikkal and V. Karthikeyan, "Dual input superboost DC-DC converter for solar powered electric vehicle," in IET Power Electronics, vol. 12, no. 9 , Aug. 2019, pp. 2276-2284.

[24]. S. Athikkal, G. Guru Kumar, K. Sundaramoorthy and A. Sankar, "A Non-Isolated BridgeType DC-DC Converter for Hybrid Energy Source Integration," in IEEE Transactions on Industry Applications, vol. 55, no. 4, July-Aug. 2019, pp. 4033-4043.

[25]. T. Jalilzadeh, N. Rostami, E. Babaei and S. H. Hosseini, "Multiport DC-DC Converter with Step-Up Capability and Reduced Voltage Stress on Switches/Diodes," in IEEE Transactions on Power Electronics, vol. 35, no. 11, Nov. 2020, pp. 11902-11915.

[26]. S. Moury and J. Lam, "A Soft-Switched Power Module with Integrated Battery Interface for Photovoltaic-Battery Power Architecture," in IEEE Journal of Emerging and Selected Topics in Power Electronics, vol. 8, no. 3, Sept. 2020, pp. 3090-3110.

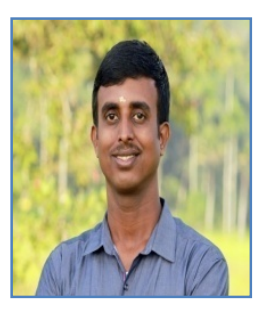

Sivaprasad Athikkal was born in Thrissur, Kerala, India, in 1989. He has received the B.Tech. Degree in Electrical and Electronics Engineering (EEE) from the University of Calicut, Thenhippalam, Kerala, India, in 2010, the M.Tech. Degree in Power Electronics from Amrita Vishwa Vidyapeetham University, Coimbatore, Tamil Nadu, India, in 2012, and the Ph.D. Degree in Electrical Engineering from the National Institute of Technology Calicut, Calicut, Kerala, India, in 2018. He is currently an Assistant Professor with the Department of EEE, SRM Institute of Science and Technology, Kattankulathur, Tamil Nadu, India. He is the recipient of Young Researcher Award 2020 given by Institute of Scholars, India. His main research interests include multiple input DC-DC converters, high voltage gain DC-DC converters, grid integration of renewable energy sources and electric vehicles. 